\title{
Lack of effect of beta-blocker on flat dose response to thiazide in hypertension: efficacy of low dose thiazide combined with beta-blocker
}

\author{
GRAHAM A MACGREGOR, RICHARD A BANKS, NIRMALA D MARKANDU, JOHN BAYLISS, \\ JOE ROULSTON
}

\begin{abstract}
Increasing the dose of a thiazide diuretic used alone in patients with essential hypertension has little further effect on blood pressure but increases the deleterious metabolic consequences of the diuretic. The effect of a beta-blocker on this flat dose response is not known. In two randomised crossover studies the effect of 12.5 $\mathrm{mg}, 25 \mathrm{mg}$, and $50 \mathrm{mg}$ hydrochlorothiazide combined with $400 \mathrm{mg}$ acebutolol was assessed. The mean fall in supine blood pressure was about $15 \%$ and was the same whatever dose of thiazide was used with the beta-blocker. As the dose of hydrochlorothiazide was increased, however, there was evidence of increasing metabolic consequences of the diuretic. The study did not define the minimum dose of diuretic, and doses of hydrochlorothiazide lower than $12.5 \mathrm{mg}$ might be as effective.

These results suggest that many patients who are being treated with a combination of a beta-blocker and a diuretic are receiving unnecessarily large amounts of the diuretic without benefit to their blood pressure and with adverse metabolic consequences.
\end{abstract}

\section{Introduction}

When a thiazide diuretic is used alone to treat high blood pressure increasing the dosage has little further effect on lowering the pressure but does increase the deleterious metabolic consequences of the diuretic-for example, hypokalaemia. ${ }^{12}$ This flat blood pressure response to the dose of diuretic has been shown with both competitive inhibitors of angiotensin II and converting enzyme inhibitors to be largely due to the increased renin release and thereby angiotensin II concentration, which maintains blood pressure in the face of the increased loss of sodium and water as the dose of diuretic is increased. ${ }^{3}{ }^{4}$ Inhibition of angiotensin converting enzyme abolishes the flat dose response to diuretics, resulting in a progressive fall in blood pressure as the dose of diuretic is increased, provided that the formation of angiotensin II is blocked. ${ }^{5}$ Beta-blockade inhibits renin release $^{6}$ and causes circulating angiotensin II concentrations to be reduced by about half. Part of the additive action of a beta-blocker and a diuretic has been attributed to the inhibition by the beta-blocker of the compensatory rise in renin release caused by the diuretic. Beta-blockers, however, appear to inhibit only sympathetically mediated renin release, and increasing amounts of diuretic combined with a betablocker may still cause a progressive compensatory rise in renin release and thereby angiotensin II concentrations. This could result in a flat dose response to the diuretic even in the presence of a beta-blocker. We therefore studied in two randomised crossover studies the effects of different doses of hydrochlorothiazide $(50 \mathrm{mg}, 25 \mathrm{mg}, 12.5 \mathrm{mg}$ ) given once a day with the beta-blocker acebutolol at a fixed amount of $400 \mathrm{mg}$ once daily (and in one phase $200 \mathrm{mg}$ acebutolol plus $12.5 \mathrm{mg}$ hydrochlorothiazide once daily) in patients with mild to moderate essential hypertension.

\section{Patients and methods}

We studied 24 patients with mild to moderate essential hypertension who had been referred to the blood pressure unit by local general

\footnotetext{
Blood Pressure Unit, Department of Medicine, Charing Cross Hospital Medical School, London W6 8RF

GRAHAM A MACGREGOR, MA, FRCP, senior lecturer and honorary consultant physician registrar

NIRMALA D MARKANDU, SRN, research assistant

JOHN BAYLISS, MA, MRCP, research fellow and honorary registrar

JOE ROULSTON, PHD, MRSC, senior biochemist

Correspondence to: Dr G A MacGregor.
} . 
practitioners. Any treatment designed to lower blood pressure was stopped at least two weeks before the study and any diuretics at least four weeks before the study. Patients were excluded if there was evidence of renal failure, ischaemic heart disease, or cerebrovascular disease or if they were taking oral contraceptives or other drugs. Informed consent was obtained from each patient. All drugs were given once daily in the morning. There were two separate studies. In the first study acebutolol $400 \mathrm{mg}$ once daily and hydrochlorothiazide $25 \mathrm{mg}$ once daily for one month were compared with acebutolol 400 $\mathrm{mg}$ once daily and hydrochlorothiazide $50 \mathrm{mg}$ once daily for one month in a randomised crossover study. Twelve patients (seven men, five women) were included in this study; eight were white and four black. The mean age was 46 years (range (29-62) and the mean supine diastolic pressure $114 \mathrm{~mm} \mathrm{Hg}$ (range 106-127 $\mathrm{mm} \mathrm{Hg}$ ). In the second study three different dose combinations were given for four weeks each, the order of administration being randomised. The three combinations were acebutolol $400 \mathrm{mg}$ with hydrochlorothiazide $12.5 \mathrm{mg}$, acebutolol $400 \mathrm{mg}$ with hydrochlorothiazide $25 \mathrm{mg}$, and acebutolol $200 \mathrm{mg}$ with hydrochlorothiazide $12.5 \mathrm{mg}$. Twelve patients (six men, six women; six white, six black) were studied. The mean age was 49 years (range 40-64) and mean supine diastolic pressure $107 \mathrm{~mm} \mathrm{Hg}$ (range $99-120 \mathrm{~mm} \mathrm{Hg}$ ). All patients were studied taking their normal diet, and no dietary advice was given.

The procedure in both studies was identical, except that in the second study after four weeks' treatment with acebutolol $200 \mathrm{mg}$ and hydrochlorothiazide $12.5 \mathrm{mg}$ daily blood pressure was also measured 24 hours after the final dose was taken. During the trial all patients were seen fortnightly in the blood pressure unit. Each patient was seen on the same day of the week at the same time of day, by the same nurse, in the same room. Blood pressure was measured in the same arm by nurses using semiautomatic ultrasound sphygmomanometers (Arteriosonde) ${ }^{7}$ with attached recorders. The measurements were therefore free from any observer bias. Supine and standing blood pressures were taken as the means of five readings taken at intervals of one to two minutes with the patients in the corresponding positions. Blood pressure after exercise was a single reading taken one minute after a standard period of treadmill exercise. Pulse rate was measured with a Cambridge 3048 pulse monitor. Weight was measured at each visit. Blood was taken for estimation of blood urea, electrolyte, creatinine, uric acid, and glucose concentrations and plasma renin activity before active treatment and at monthly intervals thereafter. Blood was taken without stasis after the patient had been sitting upright for five minutes between 10 am and 12 noon. Plasma renin activity was measured by radioimmunoassay. ${ }^{~}$ At each visit patients were asked how they felt and any side effects volunteered were recorded. Mean arterial pressure was calculated by adding one third of the pulse pressure to the diastolic pressure. All results were recorded as means \pm SEM. Statistical analysis was performed using a computer and the north eastern universities' statistical package for the social sciences.

\section{Results}

In the first study (fig 1) the mean supine blood pressure fell from $173 / 114 \pm 3 \cdot 8 / 1.9 \mathrm{~mm} \mathrm{Hg}$ with no treatment to $144 / 98 \pm 5 \cdot 7 / 3.4 \mathrm{~mm} \mathrm{Hg}$ after four weeks' treatment with acebutolol $400 \mathrm{mg}$ and hydrochlorothiazide $50 \mathrm{mg}$ and to $145 / 97 \pm 6 \cdot 1 / 4 \cdot 2 \mathrm{~mm} \mathrm{Hg}$ after four weeks' treatment with acebutolol $400 \mathrm{mg}$ and hydrochlorothiazide $25 \mathrm{mg}$. These were reductions of $15 \cdot 2 \%$ and $15 \cdot 4 \%$ respectively compared with the pretreatment value and were highly significant $(p<0 \cdot 001)$. In the second study (fig 2 ) mean supine blood pressure fell from $169 / 107 \pm 5 \cdot 6 / 1.9 \mathrm{~mm} \mathrm{Hg}$ with no treatment to $140 / 93 \pm 4 \cdot 7 / 3 \cdot 2 \mathrm{~mm} \mathrm{Hg}$ after four weeks' treatment with acebutolol and hydrochlorothiazide $25 \mathrm{mg}$; this was a reduction of $15.1 \%(\mathrm{p}<0.001)$. After four weeks' treatment with acebutolol $400 \mathrm{mg}$ and hydrochlorothiazide $12.5 \mathrm{mg}$ the mean supine blood pressure was $142 / 94+5.3 / 3.6 \mathrm{~mm} \mathrm{Hg}$, which represented a $13.8 \%$ reduction $(\mathrm{p}<0.001)$. There was no significant difference in the blood pressure achieved or the absolute or percentage fall in blood pressure with $12.5 \mathrm{mg}, 25 \mathrm{mg}$, or $50 \mathrm{mg}$ of hydrochlorothiazide combined with $400 \mathrm{mg}$ of acebutolol. After four weeks' treatment with acebutolol $200 \mathrm{mg}$ and hydrochlorothiazide $12.5 \mathrm{mg}$ (fig 3) mean average supine blood pressure had fallen to $150 / 99 \pm$ $4.9 / 3.4 \mathrm{~mm} \mathrm{Hg}(\mathrm{p}<0.01)$; this represented a $9.4 \%$ fall. Although this blood pressure was higher than that after four weeks' treatment with $400 \mathrm{mg}$ acebutolol and $12.5 \mathrm{mg}$ hydrochlorothiazide, it was not significantly different. It was, however, significantly higher than the blood pressure after four weeks' treatment with acebutolol $400 \mathrm{mg}$ and hydrochlorothiazide $25 \mathrm{mg}(\mathrm{p}<0 \cdot 01)$. Mean supine blood pressure measured 24 hours after the final dose of acebutolol $200 \mathrm{mg}$ with

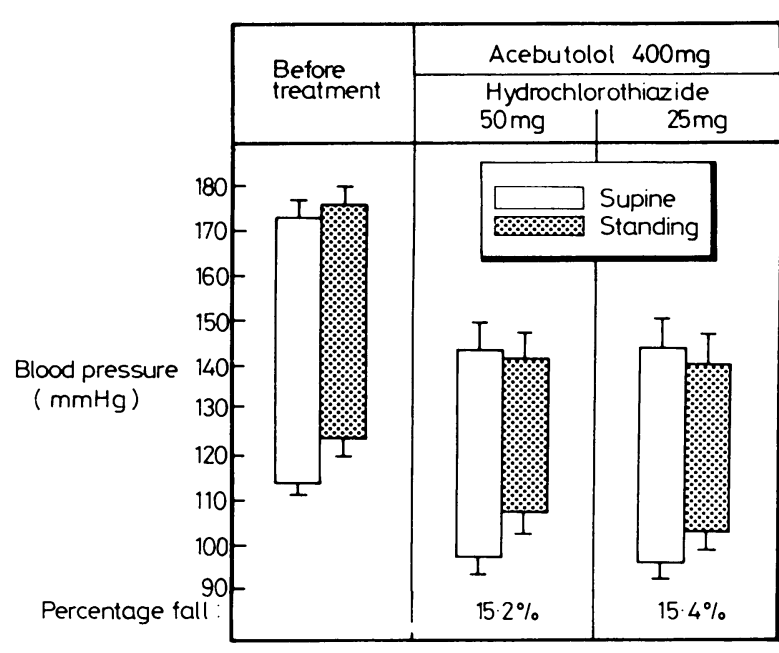

FIG $1-$ Mean \pm SEM blood pressure before and after treatment with acebutolol $400 \mathrm{mg}$ once daily and hydrochlorothiazide either $50 \mathrm{mg}$ or $25 \mathrm{mg}$ once daily for one month in 12 patients.

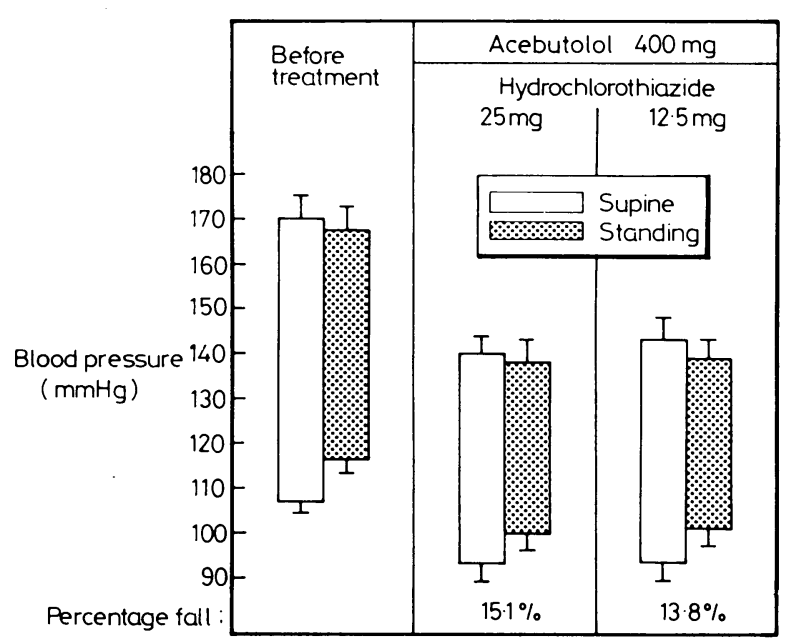

FIG 2-Mean $\pm S E M$ blood pressure before and after treatment with acebutolol $400 \mathrm{mg}$ once daily and hydrochlorothiazide either $25 \mathrm{mg}$ or $12.5 \mathrm{mg}$ once daily for one month in 12 patients.

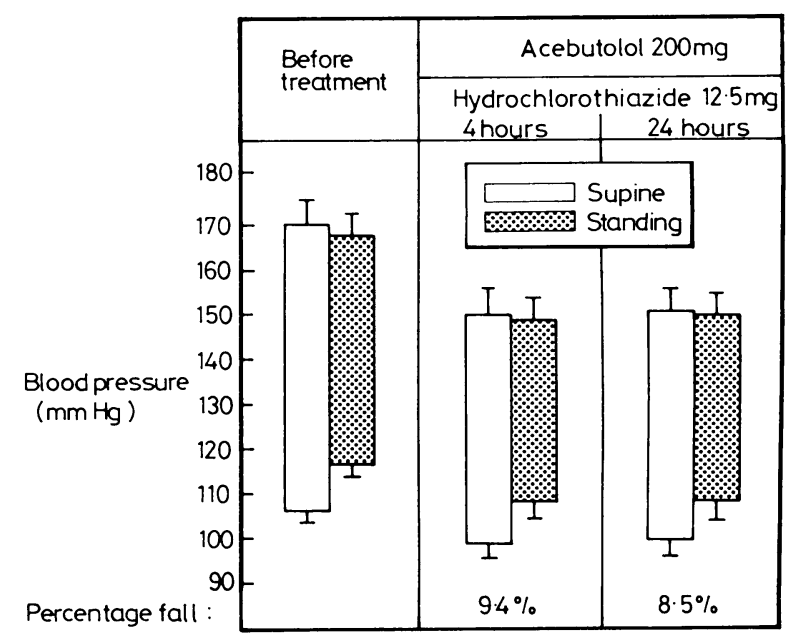

FIG 3-Mean \pm SEM blood pressure before and after treatment with acebutolol $200 \mathrm{mg}$ once daily and hydrochlorothiazide 12.5 mg once daily for one month measured four and 24 hours after last dose. 
hydrochlorothiazide $12.5 \mathrm{mg}$ was $151 / 100+5.7 / 3.2 \mathrm{~mm} \mathrm{Hg}$-that is, almost identical with that measured four hours after the final dose.

Standing blood pressure (figs 1, 2, and 3) and blood pressure after exercise (table I) showed changes similar to supine blood pressure in both studies.

Pulse rates supine, standing, and after exercise were significantly reduced four hours after the end of treatment with each combination. Twenty four hours after the end of treatment with acebutolol $200 \mathrm{mg}$ and hydrochlorothiazide $12.5 \mathrm{mg}$ the pulse rate was still reduced compared with pretreatment values but the reduction was significant only on standing (tables I and II).

Blood measurements-Plasma potassium and chloride concentrations fell significantly and plasma bicarbonate concentrations rose in the first study with both $25 \mathrm{mg}$ and $50 \mathrm{mg}$ hydrochlorothiazide combined with $400 \mathrm{mg}$ acebutolol (table II). In the second study there was no significant change in these concentrations with either $25 \mathrm{mg}$ or 12.5 $\mathrm{mg}$ hydrochlorothiazide. Plasma uric acid concentration was increased after all drug combinations and was not significantly different between the combinations. Blood urea concentration increased significantly with hydrochlorothiazide $50 \mathrm{mg}$. In the first study plasma renin activity rose from $0.77: 0.15 \mathrm{nmol} / \mathrm{l} / \mathrm{h}(1 \cdot 0: 0.2 \mathrm{ng} / \mathrm{ml} / \mathrm{h})$ before treatment to $1.48 ! 0.31 \mathrm{nmol} / 1 / \mathrm{h}(1.9 ! 0.4 \mathrm{ng} / \mathrm{ml} / \mathrm{h})(\mathrm{p}<0.05)$ after four weeks' treatment with hydrochlorothiazide $50 \mathrm{mg}$ and acetbutolol $400 \mathrm{mg}$ (table II). With hydrochlorothiazide $25 \mathrm{mg}$ plasma renin activity did not change and was $0.73 \div 0.15 \mathrm{nmol} / 1 / \mathrm{h}(0.95: 0.2$ $\mathrm{ng}(\mathrm{ml} / \mathrm{h})$, at the end of treatment. The difference in plasma renin activity after four weeks' treatment with $50 \mathrm{mg}$ or $25 \mathrm{mg}$ of hydrochlorothiazide was significant $(\mathrm{p}<0.003)$. In the second study plasma renin activity was $0.53: 0.23 \mathrm{nmol} / \mathrm{l} / \mathrm{h}(0.69: 0.3 \mathrm{ng} / \mathrm{ml} / \mathrm{h})$ before treatment. After four weeks' treatment with $25 \mathrm{mg}$ hydrochlorothiazide and acebutolol $400 \mathrm{mg}$ it was $0.52: 0.15 \mathrm{nmol} / 1 / \mathrm{h}(0.70: 0.2 \mathrm{ng} / \mathrm{ml} / \mathrm{h})$, and after four weeks' treatment with acebutolol $400 \mathrm{mg}$ and hydrochlorothiazide $12.5 \mathrm{mg}$ it had fallen to $0.4: 0.15 \mathrm{nmol} / 1 / \mathrm{h}(0.52: 0.2$ $\mathrm{ng} / \mathrm{ml} / \mathrm{h})$.

Weight and side effects-A significant fall in weight occurred with the $50 \mathrm{mg}$ dose of hydrochlorothiazide, but otherwise changes in weight were not significant. No serious side effects were reported in either study. Four patients had slight headaches, but this did not necessitate stopping treatment.

\section{Discussion}

This study shows that a once daily combination of a betablocker, acebutolol, and a thiazide diuretic, hydrochlorothiazide, is effective in lowering blood pressure in mild to moderate essential hypertension. The fall in blood pressure was identical, however, whether $12.5 \mathrm{mg}, 25 \mathrm{mg}$, or $50 \mathrm{mg}$ hydrochlorothiazide was used in combination with $400 \mathrm{mg}$ acebutolol. This flat dose response to a thiazide diuretic in the presence of a beta-blocker shows that low doses of thiazide diuretics may be used combined with a beta-blocker to treat hypertension in a similar fashion to when the diuretics are used alone. ${ }^{12}$ Our study does not, however, define the lowest dose of a thiazide diuretic that is effective as we did not use a dose lower than $12.5 \mathrm{mg}$ hydrochlorothiazide. This flat dose response is important because of the increasing adverse metabolic consequences of using unnecessarily high doses of thiazide diuretics. ${ }^{1}$ This was seen in our study particularly when $50 \mathrm{mg}$ hydrochlorothiazide was used in combination with the beta-blocker: compared with control values there was a significant increase in blood urea and bicarbonate concentrations and plasma renin activity and a significant fall in plasma potassium and chloride concentrations and weight. The significant fall in plasma potassium concentration occurred even though the beta-blocker is claimed to mitigate the fall in plasma potassium concentration that occurs with diuretics.

The flat dose response of blood pressure to thiazide diuretics alone is at least partly due to the compensatory rise in renin release and angiotensin II concentration caused by the diuretic as the dose is increased. ${ }^{3}$ Beta-blockers inhibit sympathetically mediated renin release from the juxta glomerular apparatus and thereby cause a fall in circulating angiotensin II concentrations. This has been claimed to be part of the mechanism whereby beta-blockers alone may lower blood pressure. ${ }^{5}$ Suppression of renin release and thereby angiotensin II by beta-blockers in the presence of a diuretic has also been claimed to be part of their additive action. Our study shows that despite the presence of a

TABLE I-Mean :SEM blood pressure and pulse rate one minute after treadmill exercise $(n=12)$

\begin{tabular}{|c|c|c|c|c|}
\hline \multicolumn{2}{|c|}{ Treatment } & \multirow{2}{*}{$\begin{array}{c}\text { Hours after } \\
\text { treatment }\end{array}$} & \multirow[b]{2}{*}{ Blood pressure $(\mathrm{mm} \mathrm{Hg})$} & \multirow{2}{*}{$\begin{array}{c}\text { Pulse } \\
\text { (beats } / \mathrm{min} \text { ) }\end{array}$} \\
\hline $\begin{array}{c}\text { Acebutolol } \\
(\mathrm{mg})\end{array}$ & $\begin{array}{c}\text { Hydrochlorothiazide } \\
(\mathrm{mg})\end{array}$ & & & \\
\hline \multicolumn{5}{|c|}{ First study } \\
\hline $\begin{array}{l}\text { Before treatment } \\
400 \\
400\end{array}$ & $\begin{array}{l}50 \\
25\end{array}$ & $\begin{array}{l}4 \\
4\end{array}$ & $\begin{array}{c:c}184 / 114 & 5 \cdot 6 / 2 \cdot 6 \\
143^{* * *} / 100^{* * *} & 6 \cdot 3 / 4 \cdot 1 \\
144^{* * *} / 98^{* * *} & 3 \cdot 7 / 2 \cdot 6\end{array}$ & $\begin{array}{c:c}97 * 4 \\
84 * * * & 4 \\
83 * * * & 3\end{array}$ \\
\hline \multicolumn{5}{|c|}{ Second study } \\
\hline $\begin{array}{l}\text { Before treatment } \\
400 \\
400\end{array}$ & $\begin{array}{l}25 \\
12 \cdot 5\end{array}$ & $\begin{array}{l}4 \\
4\end{array}$ & $\begin{array}{c:c}193 / 114+7 \cdot 9 / 3 \cdot 0 \\
151^{* * *} / 96^{* * *} & 6 \cdot 0 / 4 \cdot 0 \\
152^{* * *} / 99^{*} & 8 \cdot 0 / 4 \cdot 9\end{array}$ & $\begin{array}{c}99 \div 3 \\
88^{* * *}+4 \\
82^{* * *}+3\end{array}$ \\
\hline 200 & $12 \cdot 5$ & $\left\{\begin{array}{r}4 \\
4 \\
24\end{array}\right.$ & $\begin{array}{cc:c}161^{* * *} / 105^{*}: & 7 \cdot 0 / 2 \cdot 9 \\
171^{* * *} / 105^{* *}: & 6 \cdot 0 / 3 \cdot 0\end{array}$ & $\begin{array}{c}87 * 3 \\
95+4\end{array}$ \\
\hline
\end{tabular}

Significance of difference from pretreatment value: ${ }^{*} \mathrm{p}-0.05 ;{ }^{* *} \mathrm{p} \quad 0.01 ;{ }^{* *} \mathrm{p} \quad 0.001$.

TABLE II-Effect of treatment on plasma biochemistry, weight, and pulse rate (expressed as means $\perp S E M)(n=12)$

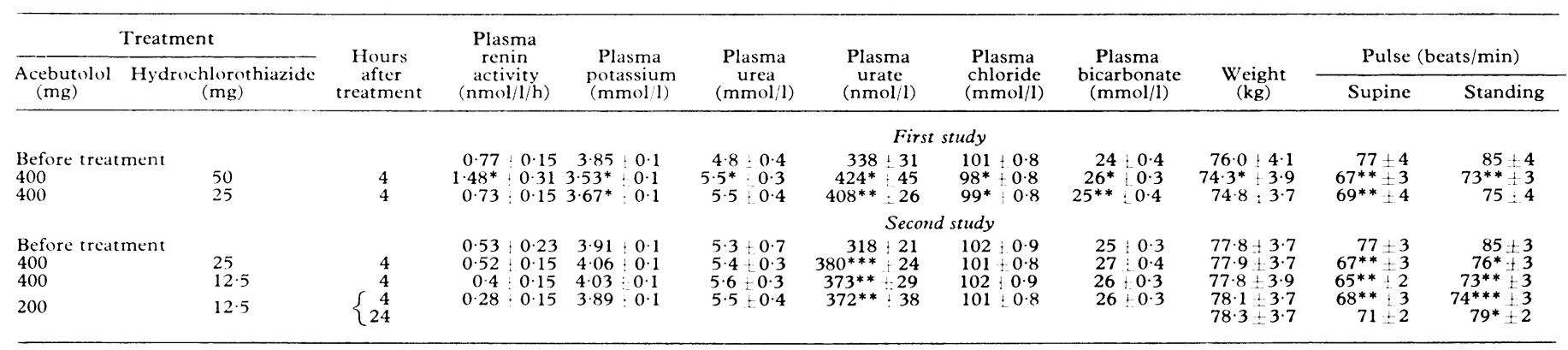

Significance of difference from pretreatment value: ${ }^{*} \mathrm{p} \cdot 0.05 ; * * \mathrm{p} \cdot 0.01 ; * * * \mathrm{p}: 0.001$.

Conversion: SI to traditional units-Plasma renin activity: $1 \mathrm{nmol} / 1 / \mathrm{h} \approx 1.3 \mathrm{ng} / \mathrm{ml} / \mathrm{h}$. Potassium: $1 \mathrm{nmol} / 1=1 \mathrm{mEq} / \mathrm{l}$. Urea: $1 \mathrm{mmol} / 1 \approx 6 \mathrm{mg} / 100 \mathrm{ml}$. Urate: $1 \mathrm{nmol} / \mathrm{l} \approx 16.8$ $\mathrm{ng} / 100 \mathrm{ml}$. Chloride: $1 \mathrm{mmol} / \mathrm{l}=1 \mathrm{mEq} / \mathrm{l}$. Bicarbonate: $1 \mathrm{mmol} / 1=1 \mathrm{mEq} / \mathrm{l}$. 
beta-blocker a progressive rise in plasma renin activity occurs with increasing doses of a thiazide diuretic, albeit this is a lower rise than would occur if the patients were taking a thiazide diuretic alone. Plasma renin activity was significantly higher after four weeks' treatment with acebutolol $400 \mathrm{mg}$ and hydrochlorothiazide $50 \mathrm{mg}$ than before treatment. With $12.5 \mathrm{mg}$ of hydrochlorothiazide and acebutolol $400 \mathrm{mg}$ plasma renin activity was actually lower than before treatment, though not significantly so. This increased release of renin with increasing doses of diuretic despite the presence of a beta-blocker is probably part of the mechanism explaining the flat dose response to the diuretic. Further work needs to be done, however, using either competitive inhibitors of angiotensin II or converting enzyme inhibitors in conjunction with a beta-blocker and a diuretic, to clarify this point.

The effect of reducing the dose of the beta-blocker from 400 $\mathrm{mg}$ to $200 \mathrm{mg}$ was also examined in combination with $12.5 \mathrm{mg}$ hydrochlorothiazide. Acebutolol $200 \mathrm{mg}$ significantly lowered blood pressure by $9.4 \%$ while acebutolol $400 \mathrm{mg}$ lowered it by $13.8 \%$. Thus it appears that, when used in combination with hydrochlorothiazide, $400 \mathrm{mg}$ acebutolol is more effective in lowering blood pressure than $200 \mathrm{mg}$, but further stu 'ies need to be done to clarify the upper and lower limits of the dose response curve for the beta-blocker when used with a diuretic. The effective half life of beta-blockers in lowering blood pressure is longer than might be expected from the clearance of the drugs from the plasma. The duration of action of the lowest dose combination used in this study-acebutolol $200 \mathrm{mg}$ with hydrochlorothiazide $12.5 \mathrm{mg}$ - was therefore examined. The significant reduction in mean blood pressure achieved with this combination at four hours was unchanged at 24 hours. Thus it is reasonable to expect that the combination of $400 \mathrm{mg}$ acebutolol with 12.5 mg hydrochlorothiazide would also be effective for 24 hours after dosing, although this was not examined in this study.

This study did not define the minimum dose of diuretic, and a dose of hydrochlorothiazide less than $12.5 \mathrm{mg}$ might possibly be as effective. In the meantime, our results suggest that many preparations that combine a beta-blocker and a diuretic contain too much thiazide diuretic. This higher dose of diuretic will have $\stackrel{\text { w }}{\frac{7}{7}}$ adverse metabolic consequences to the patient without further lowering the blood pressure. A low but effective dose of diuretic $\frac{\Omega}{c}$ is less likely to result in adverse effects and should reduce the cost $\widehat{O}$ of treatment, conferring obvious advantages in terms of patient $\overline{\bar{J}}$ acceptability and compliance. Our results also indicate that in patients whose blood pressure is not controlled by the lower dose $\mathbb{\Phi}$ of diuretic combined with a beta-blocker there is little point in $\frac{\Omega}{\rho}$

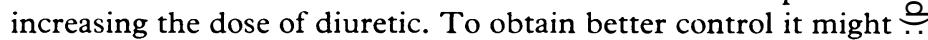
be more appropriate to add a third drug such as a vasodilator or $\overrightarrow{\vec{F}}$ change to an angiotensin converting enzyme inhibitor combined with a diuretic, or to a calcium entry antagonist.

\section{References}

' Cranston WI, Juel-Jensen BE, Semmence AM, Handfield-Jones RPC Forbes JA, Mutch LMM. Effects of oral diuretics on raised arteria pressure. Lancet 1963; ii :966-70.

2 Berglund G, Andersson O. Low doses of hydrochlorothiazide in hypertension: antihypertensive and metabolic effects. Eur $\mathcal{F}$ Clin Pharmacol $1976 ; 10: 177-82$.

${ }^{3}$ Leonetti G, Terzoli L, Sala C, Bianchini C, Sernesi L, Zanchetti A. Relationship between the hypotensive and renin-stimulating actions of diuretic therapy in hypertensive patients. Clinical Science and Molecular $\infty$ Medicine 1978;55:307-9S

4 Ibsen H, Leth A, Hollnagel H, Kappelgaard AM, Nielsen MK, Giese J. హे Renin-angiotensin system in mild essential hypertension. The functional significance of angiotensin II in untreated and thiazide-treated hyper- $\vec{\Delta}$

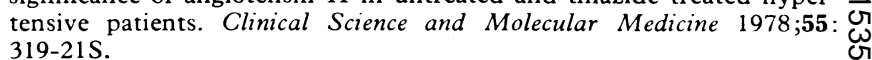

5 MacGregor G, Markandu ND, Banks RA, Bayliss J, Roulston JE, Jones 음 JC. Captopril in essential hypertension; contrasting effects of adding hydrochlorothiazide or propranolol. Br Med f 1982;284:693-6.

${ }^{6}$ Buhler FR, Laragh JH, Baer L, et al. Propranolol inhibition of renin secretion. A specific approach to diagnosis and treatment of renindependent hypertensive disease. $N$ Engl f Med 1972;287:1209-4.

7 George CF, Lewis PJ, Petrie A. Clinical experience with use of ultrasound $\vec{\omega}$ sphygmomanometer. Br Heart $\mathcal{F} 1975 ; 37: 804-7$.

${ }^{*}$ Roulston JE, MacGregor GA. Measurement of plasma renin activity by radioimmunoassay after prolonged cold storage. Clin Chim Acta $1978 ; 88: 45-8$.

(Accepted 10 March 1983) 